Masna Manurung, Ahmad Sokip \& Palupi Puspitorini, 2016. Pengaruh Pemberian Dosis Pupuk

Kandang dan Jenis Mulsa terhadap Pertumbuhan dan Produksi Tanaman Semangka (Citrullus vulgaris,Schard) di Musim Hujan. Journal Viabel Pertanian. (2016), 10(1) - 37-52

\title{
PENGARUH PEMBERIAN DOSIS PUPUK KANDANG DAN JENIS MULSA TERHADAP PERTUMBUHAN DAN PRODUKSI TANAMAN SEMANGKA (Citrullus vulgaris,Schard) DI MUSIM HUJAN
}

\author{
Masna Manurung1), Ahmad Sokip2), Palupi Puspitorini2) \\ 1). Prodi Agroteknologi Fakultas pertanian Universitas Gajah Putih Takengon,Aceh Tengah \\ 2). Program Studi Agroteknologi, Fakultas Pertanian, Universitas Islam Balitar, Blitar
}

\begin{abstract}
This research have go to influence interaction between cow manure and kind of mulch, also influence the best dose cow manure dan the best mulch to growth and water melon (Citrullus vulgaris,Schard) plant production at rainy season winner variety. The study has arranged by Random Designed Group (RAK) factorial with two treatments and 3 replications. Dose of cow manure in the first factor with 3 level,that is $P_{1}=5$ ton- ha ${ }^{2}$ cow manure, $P_{2}=10$ ton- ha ${ }^{2}$ and $P_{3}=15$ ton-ha' ${ }^{2}$. Second factor that is kind of mulch (M) with 3 level, that is $M_{0}=$ no mulch, $M_{1}=$ straw mulch and $M_{2}=$ black silver mulch. Parameters that to be perceived to covet length of plant, leaf quantity, quality fruite and diameter fruite. The data is analyzed to use it analysis Of Variant (ANOVA), if influency to be continued with test DMRT 5\%. The result of studies refer that, 1). Interactions between cow manure 10 ton- $^{2}\left(P_{2}\right)$ silver and black mulch $\left(M_{2}\right)$ give the best influence in growing and watermelon plant productions. 2) giving fertilizer at all of treatment not influence about growing and water melon plant productions. 3 ) the kind of mulch treatment $(M)$ give it influence about all of parameters . and black and silver mulch $\left(M_{2}\right)$ give the best treatment about growing and water melon plant productions.
\end{abstract}

Key Word : cow manure, mulch, watermelon

\section{PENDAHULUAN}

Sektor pertanian mempunyai peranan penting dalam perekonomian nasional, di antaranya dalam memperluas lapangan kerja, meningkatkan pendapatan petani, serta meningkatkan pendapatan nasional melalui penerimaan devisa. Pembangunan pertanian di satu sisi dituntut untuk menjamin pendapatan yang layak bagi petani, sedangkan di sisi lain mampu menyediakan hasil pertanian dalam jumlah yang cukup dengan harga terjangkau oleh masyarakat.

Salah satu upaya yang ditempuh untuk meningkatkan pendapatan petanian adalah dengan cara mengusahakan komoditas pertanian yang mempunyai nilai ekonomis tinggi serta mempunyai potensi pasar yang cukup besar, baik pasardalam negeri maupun luar negeri. Sektor pertanian yang dikembangkan salah satunya adalah hortikultura yang meliputi buahbuahan, sayuran dan bunga. Buah- buahan cukup potensial untuk dikembangkan dengan pertimbangan permintaanya terus meningkat. Salah satu komoditas buah yang mempunyai prospek untuk dikembangkan adalah semangka. Lamanya umur tanamansemangka tumbuh sampai buah masak, pada kondisi lahan dan cuaca normal adalah $70-100$ hari, sejak bibit ditanam (Wihardjo, 1993). 
Masna Manurung, Ahmad Sokip \& Palupi Puspitorini, 2016. Pengaruh Pemberian Dosis Pupuk

Kandang dan Jenis Mulsa terhadap Pertumbuhan dan Produksi Tanaman Semangka (Citrullus vulgaris, Schard) di Musim Hujan. Journal Viabel Pertanian. (2016), 10(1) - 37-52

Hasil produksi Semangka mempunyai prospek yang pesat di dalam negeri. Berdasarkan Badan Pusat Stastistik (BPS,2011) perkembangan produksi tanaman semangka di Indonesia tahun 2009 mencapai 474.327 ton. Namun pada tahun 2010 produksi semangka mengalami penurunan, hasilnya hanya mencapai 348.631 ton. Penurunan produksi semangka pada tahun 2010 disebabkan banyak faktor. Beberapa factor yang mempengaruhi penurunan hasil produksi semangka dalam negeri yaitu kondisi lingkungan dan cuaca yang tidak dapat di prediksi. Sehingga menyebabkan kondisi fisiologis tanah berubah,yang mengakibatkan menurunya kondisi fisiologis tanaman semangka.sehiingga perlu dilakukan modifikasi lingkungan.

Selain kondisi lingkungan,penurunan produktifitas semangka disebabkan oleh rendahnya unsure hara yang terdapat di dalam tanah. Karena tanaman membutuhkan unsur hara dengan susunan dan perbandingan sesuai dengan perbandingan tertentu dalam proses pertumbuhan dan produksinya. Dalam hal ini pupuk dapat berfungsi sebagai penyedia dan pengganti unsur-unsur hara tersebut dengan tetap memperhatikan keseimbangan unsur hara tanah. Pupuk kandang menambah tersedianya unsur hara bagi tanaman dan mempunyai pengaruh positif terhadap sifat fisis dan kimiawi tanah, mendorong kehidupan/perkembangan jasad renik. Kadar rata-rata unsur hara pada kotoran ternak di Indonesia terutama pada pupuk kandang yang matang adalah tidak lebih dari : 0,3\% N, 0,1 \% P dan 0,3\% K.4 Unsur N, P, atau K bisa didapatkan dari tanaman atau kotoran hewan tertentu (Sutejo, M.M. 1992).

Salah satu modifikasi lingkungan perakaran tanaman di dataran medium antara lain dapat dilakukan dengan penggunaan mulsa. Mulsa menimbulkan berbagai keuntungan, baik dari aspek fisik maupun kimia tanah. Secara fisik mulsa mampu menjaga suhu tanah lebih stabil dan mampu mempertahankan kelembaban di sekitar perakaran tanaman. Penggunaan mulsa akan mempengaruhi suhu tanah. Penggunaan mulsa akan mencegah radiasi langsung matahari (Doring et al., 2006; Bareisis dan Viselga, 2002). Suhu tanah maksimum di bawah mulsa jerami pada kedalaman $5 \mathrm{~cm} 10^{\circ} \mathrm{C}$ lebih rendah dari pada tanpa mulsa, sedangkan suhu minimum $1.9^{\circ} \mathrm{C}$ lebih tinggi (Midmore, 1983; Mahmood et al., 2002; Rosniawaty dan Hamdani, 2004; Hamdani dan Simarmata, 2005).

\section{BAHAN DAN METODE A. Waktu dan Tempat}

Penelitian dilakukan pada bulan April sampai Juni 2016 di Desa Menjangan Kalung Kecamatan Garum, Kabupaten Blitar. Secara geografis desa slorok terletak pada 7.21.-7.31 lintang selatan dan 110.10.-111.40. bujur timur. Topografi desa adalah berupa dataran tinggi dengan ketinggian $300 \mathrm{mdpl}$,dengan rata-rata curah hujan mencapai $2.400 \mathrm{~mm}$ per tahun.

\section{B. Bahan dan Alat}

Bahan yang digunakan dalam penelitian ini adalah benih semangka varietas hibrida winner, pupuk Urea, SP 36, dan pupuk ZA.Sedangkan alat yang digunakan adalah cangkul, ember, sprayer, timbangan, gunting, meteran dan alat tulis.

\section{Metode Penelitian}

Penelitian ini dilakukan dilapang dengan menggunakan Rancangan Acak Kelompok (RAK) yang disusun secara faktorial dengan tiga kali ulangan. Adapun faktor dan level perlakuan sebagai berikut : 

vulgaris, Schard) di Musim Hujan. Journal Viabel Pertanian. (2016), 10(1) - 37-52

Faktor $1:$ dosis pupuk kandang

P1 : Pupuk Kandang 5 t0n-ha

P2 : Pupuk Kandang 10 t0n-ha

P3 : Pupuk Kandang 15 t0n-ha

Faktor 2: Jenis Mulsa

M0: Tanpa Mulsa

M1: Mulsa Jerami

M2: Mulsa Plastik

Dari 2 faktor diatas diperoleh 9 kombinasi perlakuan yaitu :

P1M0 P2M0 P3M0

P1M1 P2M1 P3M1

$\mathrm{P} 1 \mathrm{M} 2 \quad \mathrm{P} 3 \mathrm{M} 2 \quad \mathrm{P} 3 \mathrm{M} 2$

Dari perlakuan tersebut dihasilkan 9 Perlakuan. Setiap perlakuan diulang 3 kali sehingga didapat 27 unit percobaan. Setiap unit terdiri dari 5 tanaman sehingga diperoleh jumlah seluruh tanaman yang dibutuhkan 144 tanaman dan diambil 3 tanaman pada setiap unit sebagai sampel. Jarak antar plot $50 \mathrm{~cm}$.

Data rata rata pengamatan yang diperoleh dari percobaan dianalisis dengan menggunakan uji F pada taraf 5\%, kemudian data yang signifikan dilanjutkan dengan uji (UJD) pada taraf 5\%

\section{Pelaksanaan Penelitian}

Pelaksanaan penelitian ini meliputi :

1. Pengolahan Lahan dan Pembuatan Bedengan

Lahan yang digunakan terlebih dahulu diukur sesuai dengan luas areal yang dibutuhkan untuk penelitian, kemudian dilakukan pengolahan tanah sedalam lebih kurang $20 \mathrm{~cm}$, kemudian dibersihkan dari semua kotoran. Setelah pengolahan tanah selesai lalu dibuat plot - plot percobaan, dimana panjang plot 4 meter dan lebar 2 meter. Jarak antar plot $50 \mathrm{~cm}$ dan jarak antar ulangan $100 \mathrm{~cm}$ yang juga berfungsi sebagai parit drainase dan jalan untuk pemeliharaan.

\section{Perkecambahan}

Sebelum dilakukan perkecambahan, terlebih dahulu dilakukan perenggangan kulit biji dengan menggunakan gunting kuku, pada bagian sisinya digunting. Biji yang telah direnggangkan direndam dalam larutan obat yang terdiri dari air hangat 1 liter, 1 sendok teh Atonik, 1 sendok teh fungisida Benlate, 0,5 sendok teh bakterisida Agrept 25 WP. Lama perendaman 10 sampai 30 menit. Setelah biji diangkat dan ditiriskan sampai air tidak mengalir lagi. Kemudian biji - biji tersebut dihamparkan secara merata di atas kertas koran yang telah dibasahi dengan larutan fungisida, dimana kertas koran basah diatur dalam wadah plastik merata pada dasar dan sisi wadah setebal 5 lapis kertas koran. Di atas hamparan biji dilapisi lagi dengan kertas koran 5 lapis. Kemudian wadah diselimuti dengan dengan handuk selapis yang telah basahi dengan air hangat. Setelah itu wadah di letakkan pada tempat yang bersih dan terlindung dari sinar matahari. Penyimpanan wadah dalam kotakditerangi dengan lampu pijar 10 watt. Perkecambahan lamanya 2 x 24 jam. 

vulgaris,Schard) di Musim Hujan. Journal Viabel Pertanian. (2016), 10(1) - 37-52

\section{Pembibitan}

Benih semangka yang telah berkecambah langsung disemaikan pada media semai di polybag. Media semainya terdiri dari topsoil, pupuk kandang dan curater. Media tersebut dicampur rata dan dimasukkan kedalam polybag (ukuran $7 \mathrm{~cm} \mathrm{x} 11 \mathrm{~cm}$ ), dan dibiarkan dahulu selama dua hari.

\section{Pemupukan}

Pupuk kandang diberikan sesudah tanah diolah atau 2 minggu sebelum tanam. Dosis pupuk yang diberikan sesuai dengan perlakuan. Sedangkan untuk pupuk buatan cara pemberiannya ditaburkan secara merata pada bedengan dengan cara membuat larikan di tengah bedengan. Pupuk yang dipakai adalah pupuk NPK. Pupuk ini diberikan tiga hari sebelum semaian ditanam dibedengan, setelah itu bedengan disiram dengan air secukupnya barulah bedengan ditutup dengan mulsa.

\section{Pemasangan Mulsa}

Mulsa yang digunakan dalam penelitian adalah mulsa cangkang telur. Setelah tanah digemburkan dan dibentuk bedengan sesuai dengan ukuran kebutuhan lalu pupuk kandang dan pupuk buatan diberikan dan ditutup dengan tanah secara merata lalu disiram oleh air. Kemudian mulsa cangkang telur yaitu cangkang telur dipukul kemudian ditaburkan ke bedengan.

\section{Penanaman}

Penanaman bibit dilakukan pada pagi dan sore hari. Bibit ditanam pada lubang tanam yang telah disediakan. Bibit dari semaian polybag diambil dan dimasukkan dalam lubang tanam. Celah-celah lubang tanam ditutup dengan tanah, kemudian disiram dengan air agar tanah dengan bibit menyatu.

7. Pemeliharaan

a. Penyiraman

Penyiraman dilakukan sejak tanaman dipersemaian sampai tanaman akan dipanen. Penyiraman dilakukan setiap pagi dan sore hari. Penyiraman dihentikan lebih kurang dua minggu sebelum panen.

b. Penyisipan

Bila tanaman yang baru dipindahkan mengalami pertumbuhan yang abnormal, layu atau mati maka segera dilakukan penyisipan. Penyisipan dilakukan sampai tanaman berumur dua minggu setelah tanam..

c. Pemangkasan

Pemangkasan batang dilakukan agar batang utama tumbuh sepanjang $40-60 \mathrm{~cm}$. Adapun cabang lateran dipangkas agar buah tumbuh maksimal. Ditinggalkan batang utamanya.

\section{d. Seleksi Buah}

Seleksi buah dilakukan sebelum buah menjadi besar yaitu pada saat buah sebesar telur ayam. Buah yang dipelihara adalah buah yang pertumbuhan dan bentuknya baik. Untuk setiap cabang dipelihara hanya satu buah. 

vulgaris,Schard) di Musim Hujan. Journal Viabel Pertanian. (2016), 10(1) - 37-52

\section{Pengendalian Hama dan Penyakit}

Pengendalian hama dan penyakit dilakukan sejak pembibitan sampai tanaman akan dipanen. Pengendalian hama dan penyakit dilakukan dengan mengunakan insektisida lannate dan fungisida Benlate dan Dithane M-45. Penyemprotan dilakukan pagi atau sore hari, ini tergantung kebutuhan dan kondisi cuaca.

\section{Panen}

Penentuan saat panen penting artinya sebab berpengaruh langsung terhadap kualitas buah dan produksi. Buah yang akan dipanen mempunyai ciri-ciri tangkai buahnya telah mengering, salur-salurnya berubah warna dari hijau menjadi kecoklatan, kulit buah sudah tidak mengandung lapisan lilin. Bila buah ditepuk-tepuk dengan tangan mengandung lapisan lilin. Bila buah ditepuktepuk dengan dilakukan dengan tangan jika suaranya menggema sudah bisa dipanen, pemanenan dilakukan dengan menggunakan pisau yang tajam. Tangkai buah ikut dipotong agak panjang.

\section{Varibel Pengamatan}

Variabel pengamatan dari penelitian ini sebagai berikut :

1. Panjang tanaman $(\mathrm{cm})$

panjang tanaman diukur dari pangkal batang tanaman yang berada di permukaan tanah sampai titik tumbuh batang utama. Pengukuran tinggi tanaman dilakukan setiap minggu mulai tanaman berumur 14 HST sampai tanaman memasuki fase generatif. Pengukuran dilakukan dalam satuan sentimeter dengan menggunakan alat pengukur panjang yaitu mistar atau meteran.

2. Jumlah daun (helai)

Jumlah daun diketahui dengan cara menghitung jumlah daun maksimum dengan menghitung total daun yang terbentuk. Pengamatan dilakukan setiap minggu mulai tanaman berumur 14 HST. Daun yang dihitung yaitu daun triploid yang artinya dalam satu tangkai daun terdapat tiga helai daun. Penghitungan daun dilakukan dalam satuan helai.

3. Produksi Buah Tanaman Sampel Perplot (kg)

Buah pada tanaman sampel yang telah dipanen perplotnya ditimbang berat seluruhnya.

4. Diameter Buah $(\mathrm{cm})$

Diameter buah diukur dengan terlebih dahulu mengukur keliling lingkaran buah, lalu dihitung dengan rumus :

Keliling lingkaran $=2 \pi \mathrm{r}$

$\mathrm{r}=$ Keliling lingkaran $/ 2 \pi$

Dimana $r$ adalah jari-jari

Jadi Diameter buah $=\mathrm{r} \times 2$

\section{Hasil Pengamatan Pengamatan Panjang Tanaman (cm)}

Hasil analisis ragam (Anova) 5\% menunjukkan bahwa perlakuan pupuk kandang (P) dan jenis mulsa (M) tidak terdapat pengaruh interaksi yang nyata terhadap panjang tanaman pada semua umur pengamatan $(14,28$, dan 42 HST), 
Masna Manurung, Ahmad Sokip \& Palupi Puspitorini, 2016. Pengaruh Pemberian Dosis Pupuk

Kandang dan Jenis Mulsa terhadap Pertumbuhan dan Produksi Tanaman Semangka (Citrullus vulgaris,Schard) di Musim Hujan. Journal Viabel Pertanian. (2016), 10(1) - 37-52

Pada pengamatan perlakuan media tanam (P) di semua umur pengamatan tidak terdapat perbedaan yang nyata pada peubah tinggi tanaman. Perlakuan P1 (pupuk kandang5 ton-ha), P2 (pupuk kandang 10 ton-ha), P3 (pupuk kandang 15 ton-ha) menghasilkan nilai rata-rata tinggi tanaman yang tidak berbeda nyata pada semua umur pengamatan yaitu umur 14,28 dan 42 HST.

Pada pengamatan perlakuan jenis mulsa $(\mathrm{M})$, terdapat pengaruh yang nyata pada panjang tanaman pada semua umur pengamatan. Nilai rata-rata panjang tanaman yang paling baik atau berbeda nyata dengan perlakuan lainnya di peroleh dari perlakuan M2 (mulsa plastik) dan nilai rata-rata terendah terdapat pada perlakuan M0 (tanpa mulsa) namun tidak berbeda nyata dengan nilai rata-rata pada perlakuan M1 (mulsa jerami). Hasil selengkapnya disajikan dalam tabel 3 berikut ini :

Tabel 3. Rata-Rata Panjang Tanaman (cm) Pada Dosis Pupuk (P) Dan Jenis Mulsa (M) Pada Umur Pengamatan 14, 28 dan 42 HST.

\begin{tabular}{cccc}
\hline Perlakuan & & Umur Pengamatan & \\
& 14 HST & 28 HST & 42 HST \\
\hline Pupuk kandang & & & \\
P1 & $14.33 \mathrm{a}$ & $43.81 \mathrm{a}$ & $156.85 \mathrm{a}$ \\
P2 & $14.87 \mathrm{a}$ & $43.77 \mathrm{a}$ & $150.26 \mathrm{a}$ \\
P3 & $15.07 \mathrm{a}$ & $45.84 \mathrm{a}$ & $170.07 \mathrm{a}$ \\
\hline UJD 5\% & 1.74 & 8.79 & 15.46 \\
\hline Mulsa & & & $116.92 \mathrm{a}$ \\
M0 & $12.40 \mathrm{a}$ & $31.29 \mathrm{a}$ & $170.33 \mathrm{~b}$ \\
M1 & $13.98 \mathrm{a}$ & $44.99 \mathrm{ab}$ & $161.99 \mathrm{~b}$ \\
M2 & $17.88 \mathrm{a}$ & $59.14 \mathrm{~b}$ & \\
\hline
\end{tabular}


Masna Manurung, Ahmad Sokip \& Palupi Puspitorini, 2016. Pengaruh Pemberian Dosis Pupuk

Kandang dan Jenis Mulsa terhadap Pertumbuhan dan Produksi Tanaman Semangka (Citrullus vulgaris,Schard) di Musim Hujan. Journal Viabel Pertanian. (2016), 10(1) - 37-52
UJD5\%
1.74
8.79
15.46

Sumber : Data SPSS yang diolah.

Keterangan: Angka yang diikuti huruf yang sama pada kolom yang sama menunjukkan tidak berbeda nyata pada Uji Jarak Duncan (UJD 5\%). HST = hari setelah tanam.

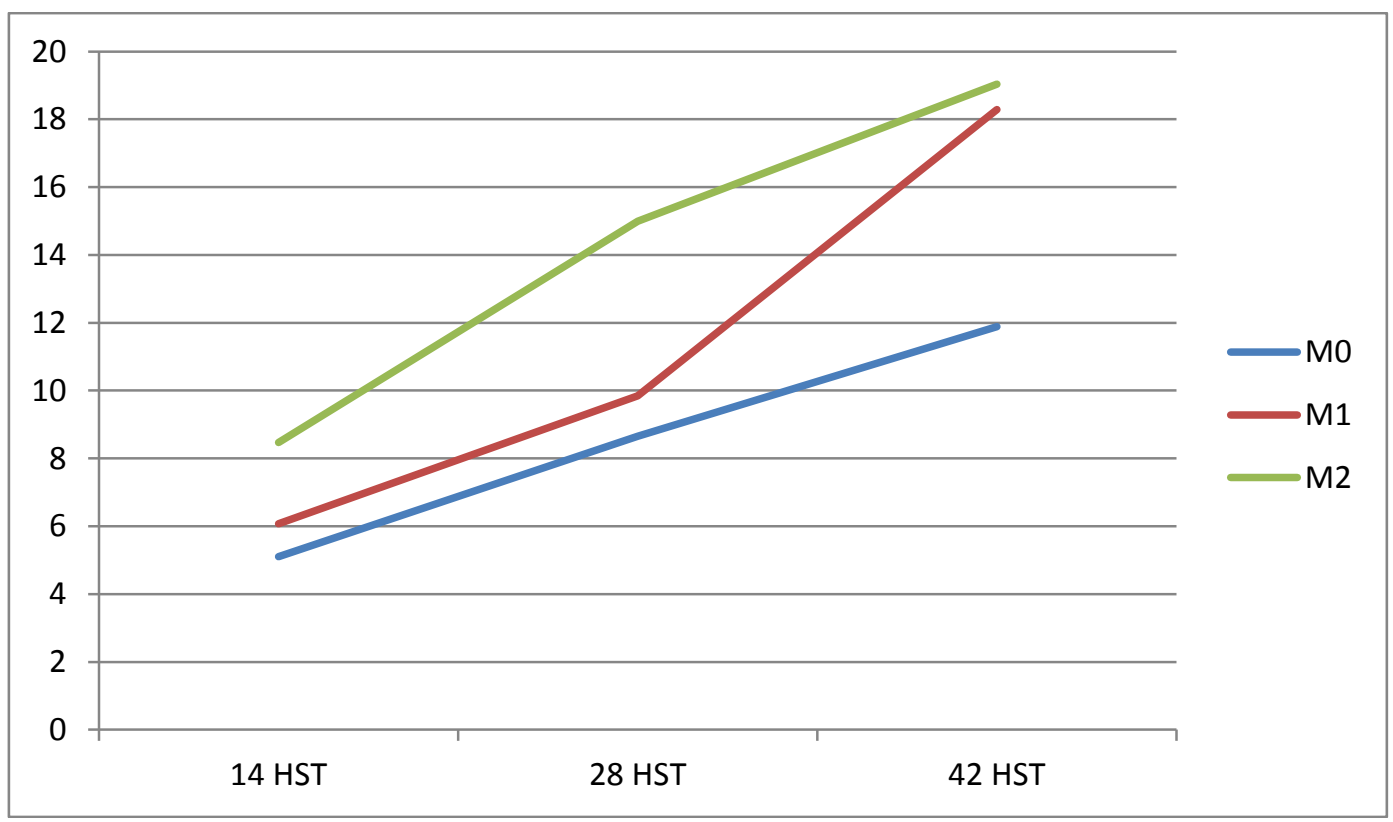

Gambar 1. Grafik Panjang Tanaman Semangka Terhadap Jenis Mulsa Pada Umur 14,28 dan 42 HST

\section{Jumlah Daun (helai)}

Hasil analisis sidik ragam (Anova) 5\% menunjukkan bahwa perlakuan pupuk kandang (P) dan jenis mulsa $(\mathrm{M})$ tidak terdapat pengaruh interaksi yang nyata terhadap jumlah daun pada semua umur pengamatan (14, 28, dan 42 HST).

Pengaruh perlakuan pupuk kandang (P) pada umur pengamatan 14 HST, 28 HST dan 42 HST tidak memberikan pengaruh nyata pada peubah jumlah daun. Pada perlakuan jenis mulsa (M) pada umur 14 HST , 28 HST dan 42 HST memberikan pengaruh yang nyata pada peubah jumlah daun terjadi.

Hasil selengkapnya disajikan dalam Tabel 4.

\section{Bobot Segar Buah Saat Panen (kg)}

Berdasarkan data hasil analisis sidik ragam (Anova) 5\% menunjukkan bahwa perlakuan dosis pupuk $(\mathrm{P})$ dan jenis mulsa $(\mathrm{M})$ terdapat pengaruh interaksi yang sangat nyata terhadap bobot buah pada saat panen.

Pengaruh interaksi antara perlakuan dosis pupuk kandang (P) dan jenis mulsa (M) pada peubah luas daun memberikan pengaruh yang sangat nyata / signifikan pada setiap perlakuan. 
Masna Manurung, Ahmad Sokip \& Palupi Puspitorini, 2016. Pengaruh Pemberian Dosis Pupuk

Kandang dan Jenis Mulsa terhadap Pertumbuhan dan Produksi Tanaman Semangka (Citrullus vulgaris,Schard) di Musim Hujan. Journal Viabel Pertanian. (2016), 10(1) - 37-52

Hasil uji UJD 5\% menunjukkan bahwa perlakuan kombinasi terbaik dihasilkan oleh perlakuan P3M2akan tetapi tidak berbeda nyata dengan perlakuan P2M2. Perlakuan perlakuan dosis pupuk kandang15 ton-ha (P3) dan 10 ton-ha (P2) mempunyai rata-rata terbaik dan berbeda nyata dari pada perlakuan dosis pupuk lain. Sedangkan perlakuan jenis mulsa yang terbaik dihasilkan oleh mulsa plastic (M2) dan berbeda nyata dengan perlakuan mulsa yang lain.

Tabel 4. Rata-Rata Jumlah Daun (Helai) Pada Dosis Pupuk Kandang (P) Dan Jenis Mulsa (M) Pada Umur Pengamatan 14, 28 dan 42 HST.

\begin{tabular}{|c|c|c|c|c|}
\hline \multirow{2}{*}{ Perlakuan } & \multicolumn{4}{|c|}{ Umur Pengamatan } \\
\hline & \multicolumn{2}{|c|}{$14 \mathrm{HST}$} & $28 \mathrm{HST}$ & $42 \mathrm{HST}$ \\
\hline \multicolumn{5}{|c|}{ Pupuk kandang } \\
\hline $\mathrm{P} 1$ & \multicolumn{2}{|l|}{$5.99 \mathrm{a}$} & $10.96 \mathrm{a}$ & $15.20 \mathrm{a}$ \\
\hline $\mathrm{P} 2$ & \multicolumn{2}{|l|}{$6.81 \mathrm{a}$} & $11.14 \mathrm{a}$ & $16.47 \mathrm{a}$ \\
\hline P3 & \multicolumn{2}{|l|}{$6.84 a$} & $11.40 \mathrm{a}$ & $17.29 \mathrm{a}$ \\
\hline UJD 5\% & \multicolumn{2}{|c|}{2.54} & 7.15 & 8.37 \\
\hline \multicolumn{5}{|l|}{ Mulsa } \\
\hline M0 & $5.10 \mathrm{a}$ & $\mathrm{a}$ & $8.66 \mathrm{a}$ & $11.88 \mathrm{a}$ \\
\hline M1 & $6.07 \mathrm{a}$ & $\mathrm{a}$ & $9.84 \mathrm{ab}$ & $18.29 \mathrm{~b}$ \\
\hline M2 & $8.47 \mathrm{a}$ & $\mathrm{a}$ & $14.99 \mathrm{~b}$ & $19.03 b$ \\
\hline UJD 5\% & 2.5 & & 7.15 & 8.37 \\
\hline
\end{tabular}

Sumber : Data SPSS yang diolah.

Keterangan: Angka yang diikuti huruf yang sama pada kolom yang sama menunjukkan tidak berbeda nyata pada Uji Jarak Duncan (UJD) 5\%. HST = hari setelah tanam. 
Jurnal Viabel Pertanian Vol. 10 No.1 April 2016

p-ISSN: 1978-5259 e-ISSN: 2527-3345

Copyright@UNISBA Blitar, http://viabel.unisbablitar.ejournal.web.id

Masna Manurung, Ahmad Sokip \& Palupi Puspitorini, 2016. Pengaruh Pemberian Dosis Pupuk

Kandang dan Jenis Mulsa terhadap Pertumbuhan dan Produksi Tanaman Semangka (Citrullus vulgaris,Schard) di Musim Hujan. Journal Viabel Pertanian. (2016), 10(1) - 37-52

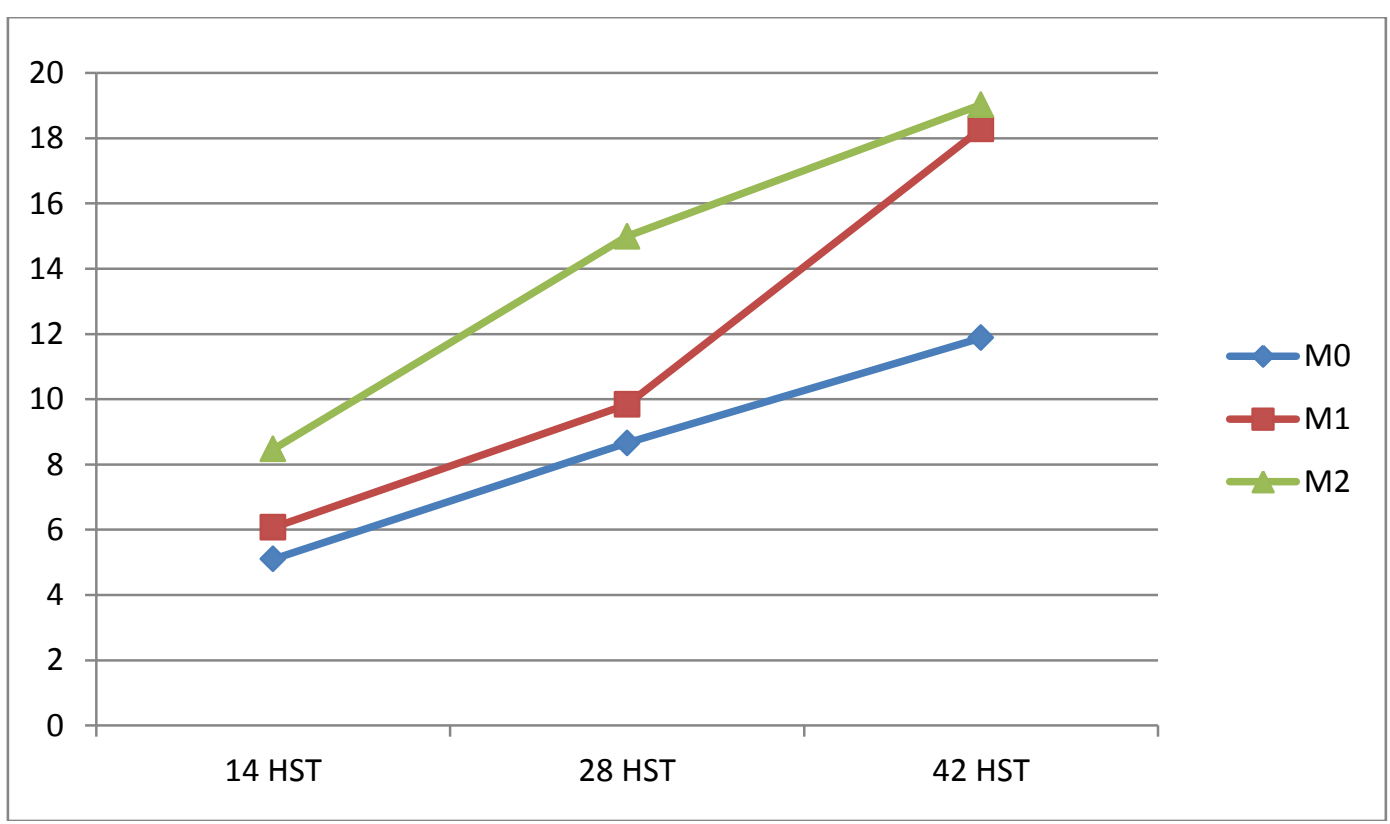

Gambar 2. Grafik Jumlah Daun Tanaman Semangka Terhadap Jenis Mulsa Pada Umur 14, 28 Dan 42 HST

Tabel 5. Rata-Rata Bobot Buah (kg) Pada Dosis Pupuk Kandang (P) Dan Jenis Mulsa (M) Pada Saat Panen.

\begin{tabular}{cc}
\hline Perlakuan & Rata-Rata \\
\hline P2M0 & $1.66 \mathrm{a}$ \\
P1M0 & $2.00 \mathrm{a}$ \\
P3M1 & $2.58 \mathrm{ab}$ \\
P1M1 & $2.66 \mathrm{ab}$ \\
P2M1 & $2.66 \mathrm{ab}$ \\
P3M0 & $2.66 \mathrm{ab}$ \\
P1M2 & $3.66 \mathrm{c}$ \\
P2M2 & $5.66 \mathrm{~d}$ \\
P3M2 & $6.00 \mathrm{~d}$ \\
\hline UJD 5\% & 0.2
\end{tabular}

Keterangan: Angka yang diikuti huruf yang sama pada kolom yang sama menunjukkan tidak berbeda nyata pada Uji Jarak Duncan 5\%. 
Masna Manurung, Ahmad Sokip \& Palupi Puspitorini, 2016. Pengaruh Pemberian Dosis

Pupuk Kandang dan Jenis Mulsa terhadap Pertumbuhan dan Produksi Tanaman

Semangka (Citrullus vulgaris,Schard) di Musim Hujan. Journal Viabel Pertanian. (2016), 10(1)-37-52

\section{Diameter Buah (cm)}

Berdasarkan data hasil analisis sidik ragam (Annova) 5\% menunjukkan bahwa perlakuan Dosis pupuk kandang $(\mathrm{P})$ dan jenis Mulsa $(\mathrm{M})$ terdapat pengaruh interaksi yang sangat nyata terhadap diameter tanaman.

Hasil analisis UJD 5\% menunjukkan bahwa perlakuan kombinasi terbaik dihasilkan oleh perlakuan P3M2 tetapi yang tidak berbeda dengan P1M2, P2M2 dan P3M2.Kombinasi perlakuan dosis pupuk kandang 15 ton-ha (P3) dan mulsa plastic (M2) dan pupuk kandang 10 ton-hadan mulsa plastic (M2) mempunyai rata-rata terbaik dan berbeda nyata dari pada perlakuan dosis pupuk kandang dan jenis mulsa lain

Tabel 6. Rata-Rata Diameter Tanaman Pada Dosis Pupuk Kandang (P) Dan Jenis Mulsa (M) Berdasarkan uji UJD 5\%

\begin{tabular}{cc}
\hline Perlakuan & Rata-Rata \\
\hline P0M2 & $10.33 \mathrm{a}$ \\
P1M0 & $11.66 \mathrm{a}$ \\
P1M1 & $15.33 \mathrm{~b}$ \\
P2M1 & $16.33 \mathrm{bc}$ \\
P3M0 & $16.66 \mathrm{bc}$ \\
P3M1 & $18.00 \mathrm{c}$ \\
P1M2 & $18.00 \mathrm{c}$ \\
P2M2 & $18.33 \mathrm{c}$ \\
P3M2 & $18.33 \mathrm{c}$
\end{tabular}

UJD 5\%

Keterangan: Angka yang diikuti huruf yang sama pada kolom yang sama menunjukkan tidak berbeda nyata pada UJD 5\%.

\section{DAFTAR PUSTAKA}

Alridiwirsah. 2008. Respon

Pertumbuhan dan Produksi Semangka Terhadap Pupuk Kandang dan Mulsa Cangkang Telur. Jurnal Agrium, Oktober 2010 Volume 16 No. 2. Medan.

Agrios, G. N. 2005. Ilmu Penyakit Tumbuhan. Edisi Kelima. Elsevier Academic Press. USA. $921 \mathrm{Hlm}$

Ansar, M. 2012. Pertumbuhan Dan Hasil Bawang Merah Pada Keragaman Ketinggian

Tempat. Disertasi. Universitas Gadjah Mada, Yogyakarta. 
Masna Manurung, Ahmad Sokip \& Palupi Puspitorini, 2016. Pengaruh Pemberian Dosis

Pupuk Kandang dan Jenis Mulsa terhadap Pertumbuhan dan Produksi Tanaman

Semangka (Citrullus vulgaris,Schard) di Musim Hujan. Journal Viabel Pertanian. (2016), 10(1)-37-52

BPS Palangka Raya. 2011. Kota

Palangka Raya dalam angka.

Buckman, HO dan Brady, NC. 1982. Ilmu Tanah. Bhatara Karya Aksara. Jakarta.

Cahyono, B. 1996. Budidaya

Semangka Hibrida Jenis Semangka Unggul Berbiji

dan Tidak Berbiji. CV.

Aneka. Solo. 102 hal.

Daryono, M., S.D. Sabari, dan S.

Pratikno. 1986. Analisis

fisik dan kimia beberapa kultivar buah semangka. Bul. Penel. Hort. $\mathrm{XIV}(2)$ : 9-16.

Doring T., U. Heimbach, T. Thieme,

M. Finckch, H. Saucke. 2006. Aspect of straw mulching in organic potatoes-I, effects on microclimate, Phytophtora infestans, and Rhizoctonia solani. Nachrichtenbl. Deut. Pflanzenschutzd. 58 (3):73-78.

Dartius, Asritanarni Munar dan Hermawan. 2011. Pupuk Bayfolan Dan Pupuk Kandang Sapi Berpengaruh Kepada Pertumbuah Dan Produksi Semangka (Citrullus vulgaris Schard). Program Studi Agroekoteknologi Fak. Pertanian UMSU Medan .journal.

Ihsan, F., A. Wahyudi, dan

Sukarmin. 2008. Teknikpembentukan semangka tetraploid untuk perakitan varietas semangka.

tanpa biji. Buletin Teknik Pertanian. 13(2):75-78.

Imam Junaidi, Sartono Joko Santosa, Endang Sri Sudalmi, 2013. Pengaruh Macam Mulsa Dan Pemangkasan Terhadap Pertumbuhan Dan Hasil Tanaman Semangka. Jurnal Inovasi Pertanian Vol. 12, No. 2, Oktober 2013

Mahmood, M., K. Farroq, A.

Hussain, R. Sher. 2002. Effect of mulching on growth and yield of potato crop. Asian J. of Plant Sci. 1(2):122-133.

Mariano, A.S.A. 2003. Pengaruh Pupuk Foska dan Mulsa Jerami terhadap Beberapa Sifat Fisik dan Kimia Tanah serta Produksi Kedelai (Glycine L. Merr). Program Studi Ilmu Tanah Departemen Tanah, Fakultas Pertanian, Institut Pertanian Bogor. Hal. 11-12.

Purnomo, S. 1993. Daya adaptasi 
Masna Manurung, Ahmad Sokip \& Palupi Puspitorini, 2016. Pengaruh Pemberian Dosis Pupuk Kandang dan Jenis Mulsa terhadap Pertumbuhan dan Produksi Tanaman Semangka (Citrullus vulgaris,Schard) di Musim Hujan. Journal Viabel Pertanian. (2016), 10(1)-37-52

semangka dan melon di dataran rendah Grati. Jurnal Hortikultura 3(1):6369.

Prajnanta, F. 1996. Agribisinis

Semangka Non-biji. Penebar Swadaya. Jakarta.

Rukmana. R. 2002. Budidaya semangka hibrida. Kanisius. Yogyakarta. 74 hal.

Rinsema, W. I. 1983. Pupuk dan Pemupukan. Penerjemah: M. Shaleh. Bhratara Karya Aksara, Jakarta.

Samadi, B . 2007. Budidaya Semangka Tanpa Biji. Kanisius. Yogyakarta. 104 hal.

Sari, A.Y.N. 2009. Pengaruh jumlah buah dan pangkas pucuk (Toping) terhadap kualitas buah pada budidaya melon (Curcumis melo L. ) dengan sistem hidroponik. Skripsi. Program Studi Hortikultura. FP-IPB.

Sarief, S. 1986. Kesuburan dan Pemupukan Tanah Pertanian. Cetakan kedua. Pustaka Buana, Bandung.

Sunarjono, H. 2000.

Prospek Berkebun Buah. Penebar Swadaya. Jakarta.

Susanti, E. 2003. Pengaruh

Ketebalan Mulsa Jerami terhadap Pertumbuhan dan Hasil Beberapa Varietas Kacang Tanah (Arachis hypogaea L.). Jurusan Budidaya Pertanian, Fakultas Pertanian Universitas Udayana, Denpasar. Skripsi. Tidak Dipublikasikan.

Soares, B. 2002. Pengaruh Dosis

Pupuk Kascing dan Jenis Mulsa terhadap Pertumbuhan dan Hasil Bawang Putih (Allium sativum L.) Varietas Lokal Sanur. Jurusan

Thomas, R.S., R.L. Franson, \& G.J.

Bethlenfalvay. 1993. Separation of VAM Fungus and Root Effects on Soil Agregation. Soil Sci. Am. J. Edition: 57: 77-31.

Wihardjo, Suwandi.1993. Bertanam

Semangka. Yogyakarta: Kanisius

Winarti, M.G.1992. Pengaruh Pupuk 
Jurnal Viabel Pertanian Vol. 7 No.4 April 2016

p-ISSN: 1978-5259 e-ISSN: 2527-3345

Copyright@UNISBA Blitar, http://viabel.unisbablitar.ejournal.web.id

Masna Manurung, Ahmad Sokip \& Palupi Puspitorini, 2016. Pengaruh Pemberian Dosis

Pupuk Kandang dan Jenis Mulsa terhadap Pertumbuhan dan Produksi Tanaman

Semangka (Citrullus vulgaris, Schard) di Musim Hujan. Journal Viabel Pertanian.

(2016), 5(4) -

dan OST Terhadap Pertumbuhan dan Produksi Tanaman semangka

(Citrulus Vulgaris Schrd). Yogyakarta: Kanisius. Budidaya Pertanian,

Fakultas Pertanian, Universitas Udayana, Denpasar. Skripsi. Tidak

Dipublikasikan.

Sobir dan Siregar F. D., 2010. Budidaya Semangka Unggul. Penebar Swadaya, Jakarta.

Marlina, Neni. 2010. Pemanfaatan Jenis Pupuk Kandang Pada Cabai Merah (Capsicum annum). Jurnal Pemanfaatan Jenis Pupuk Kandang.

Tabrani, G., R. Arisanti dan Gusmawartati. 2005. Peningkatan Produksi Bawang Merah (Allium ascalonicum L.) dengan Pemberian Pupuk KCl dan Mulsa. J. Sagu 4(1):24-31

Sutejo dan Kartasapoetra. 1990. Teknik Budidaya Tanaman Pengandi Daerah Tropik. Bina Aksara. Jakarta.

Hakim, N, M. Y.Nyakpa, A. M.Lubis, S.G. Nugroho, M.R. Saul, M.A. Diha, Goban Ban Hong dan H. H. Bailay. 1986. Dasar- Dasar Ilmu Tanah.Universitas Lampung.

Irawan, B. 2007. www.energiterbarukan.net/index.(diakses 20 desember 2015).

Purwantono, A. S. D dan Amirudin. 1994. Pengaruh Pemangkasan Cabang Dan Defoliasi Terhadap Hasil Tanaman Semangka (Citrullus vulgaris. Shard).

Poerwanto, R. 2003. Modul IX Budidaya Buah-Buahan : Pengelolaan Pohon Buah- Buahan. Program Studi Hortikulktura. Fakultas Pertanian. Institut Pertanian Bogor. Bogor.

Murray, julie. 2007. Watermelon. Minnesota. ABDO plubishing company. Hal 68.

Mohr, H. C. 1986. Watermelon breeding. p. 7-66. In M.J. Bassett (Ed.). Breeding Vegetable Crops. Avi Publishing Company, Inc., Westport, Connecticut.

Lamont, JR. W. J. 1991. The Use of Plastic Mulches for Vegetable of Holticultire. Kansas State University. 
Jurnal Viabel Pertanian Vol. 7 No.4 April 2016

p-ISSN: 1978-5259 e-ISSN: 2527-3345

Copyright@UNISBA Blitar, http://viabel.unisbablitar.ejournal.web.id

Masna Manurung, Ahmad Sokip \& Palupi Puspitorini, 2016. Pengaruh Pemberian Dosis

Pupuk Kandang dan Jenis Mulsa terhadap Pertumbuhan dan Produksi Tanaman

Semangka (Citrullus vulgaris, Schard) di Musim Hujan. Journal Viabel Pertanian. (2016), 5(4) -

Lamont, W. J. 1993. Plastic mulches for the production of vegetable crops. HorTechnology. 3 (1) : 35-38.

Handayani, M. 1996. Pengaruh Enam Jenis Mulsa Terhadap Pertumbuhan dan Hasil Semangka. (Citrullus vulgaris L.). Skripsi Fakultas Pertanian Universitas Bengkulu.

Kalie, M. B. 2004. Bertanam Semangka. Jakarta: Penebar Swadaya.

Harist, A. 2000. Petunjuk Penggunaan Mulsa. Jakarta: Penebar Swadaya. hlm. 1925

Nurtika dan Sumarna. 2001. Dosis Pupuk Kandang Untuk Tanaman Semusim. CV. Simelex Argo Media Pustaka. Depok Estat. 
